\title{
Food Safety and Food Access: A Pilot Study
}

\author{
Ellen K. Silbergeld ${ }^{1}$, Jose Augusto Frisancho ${ }^{1}$, Joel Gittelsohn ${ }^{1}$, Elizabeth T. Anderson Steeves ${ }^{1}$, \\ Matthew F. Blum ${ }^{2} \&$ Carol A. Resnick ${ }^{1}$ \\ ${ }^{1}$ Johns Hopkins Bloomberg School of Public Health, Baltimore, MD, USA \\ ${ }^{2}$ Case Western Reserve School of Medicine, Cleveland, OH, USA \\ Correspondence: Dr. Ellen Silbergeld, Bloomberg School of Public Health, Johns Hopkins University, Baltimore \\ 21205, MD, USA. Tel: 1-410-955-8678. Email: esilberg@jhsph.edu
}

Received: January 16, 2013 Accepted: February 22, 2013 Online Published: March 27, 2013

doi:10.5539/jfr.v2n2p108 URL: http://dx.doi.org/10.5539/jfr.v2n2p108

\begin{abstract}
WC 238)
Objectives: This study was designed to evaluate the feasibility of testing the hypothesis that differences in neighborhood level food access may be associated with consumer exposure to food borne microbial contamination.
\end{abstract}

Methods: This study was carried out in Baltimore MD in 2011 among selected neighborhoods defined as high or low food access. In each category, packages of chicken thighs and ground beef were purchased from small stores and supermarkets. We evaluated presence of E. coli and Staphylococcus aureus and also tested isolates for antimicrobial resistance.

Results: Microbial contamination of both chicken and beef products was highly prevalent (S. aureus-13/32 for chicken and 14/32 for beef; E. coli 21/32 for chicken and 12/32 for beef). Small stores were more likely to sell food carrying these microbes as well as MDR strains of both E. coli and $S$. aureus, and chicken was more likely to carry E. coli as compared to ground beef.

Conclusions: This is the first study of this hypothesis. While it is limited in size and in focus on one US city, the results indicate that further research is appropriate to examine neighborhood level risk factors for differential exposures to food borne microbes.

Abbreviations: S. aureus (Staphylococcus aureus); E. coli (Escherichia coli), MRSA (methicillin resistant Staphylococcus aureus), MDR (multi-drug resistant), LFA (low food access), HFA (high food access). FDA (US Food and Drug Administration), USDA (US Department of Agriculture), CLSI (Clinical and Laboratory Standards Institute).

Keywords: food safety, food access, food borne illness, Staphylococcus aureus, Escherichia coli, MRSA

$(\mathrm{WC}=3656)$

\section{Introduction}

Food access is increasingly recognized as a public health issue (NAS, 2011). It is a community/neighborhood level concept that refers to the availability, affordability and ease of getting to sources of food (Ver Ploeg \& Breneman, 2009) including the number and types of different food stores and other sources that are accessible within a given community, as well as the types and costs of foods available at these stores (Drewnowski, 2004; Powell et al., 2007b; Casagrande et al., 2011). Differences in food access have been found to contribute to both food insecurity and to health disparities among socioeconomic and ethnic groups in terms of both poorer diets and increased risks of adverse health outcomes including obesity, diabetes, and cardiovascular disease (Drewnowski, 2009; Coleman-Jensen et al., 2011; NAS, 2011).

Many studies have demonstrated that food access differs in many countries, including Canada and the US by ethnicity and socioeconomic status (SES) with the lowest access reported in low-income, urban minority neighborhoods and American Indian communities (Lewis et al. 2005; Powell et al., 2007a; Larson et al., 2009; Cerin et al., 2011; O'Connell et al., 2011; Fuller et al., 2013; Vahabi \& Damba, 2013) and among food stamp recipients (Oberholser \& Tuttle 2004; D'Angelo et al. 2011). These factors may differ in terms of importance in different cities and countries (Boone-Heinonen et al., 2011). 
Very few studies have examined the possible relationship at the neighborhood level between food access and microbial food safety despite shared sociodemographic risk factors related to both access and food borne infections (Wallace et al., 2000; Hardnett et al., 2004). Koro et al. (2010) and Signs et al. (2011) reported that ready to eat foods and fresh produce purchased in stores in low SES areas of Philadelphia had higher plate counts of yeast, mold, and bacteria (total aerobes, anaerobes, and coliforms) as compared to the same items purchased in higher SES areas. A national level analysis of listeriosis in the UK reported that incidence of diagnosed listeriosis increased with census-based indicators of neighborhood deprivation and that listeriosis cases frequently reported use of local food stores as compared to supermarkets (Gillespie et al., 2010).

No studies have directly examined differences in the prevalence of specific food borne bacteria, including pathogens, or of antimicrobial resistance in bacteria isolated from consumer products available in neighborhoods that differ in terms of food access. Studies of food borne bacteria and pathogens in food purchased at retail stores rarely identify the neighborhood source of items analyzed for microbial carriage. Exposures to antimicrobial resistant bacteria on meat and poultry products is an important aspect of food safety et al. (2011b). At the national level, this is driven by producer decisions to utilize subtherapeutic levels of antimicrobials in animal feeds (Angulod et al., 2004; Silbergeld et al., 2008). At the local level differences in frequency of health inspections at food stores and food service outlets may also be important (Darcey \& Quinlan 2011). Practices at the store or outet level can also affect food safety, such as inadequate refrigeration, stocking items past sell by dates, and practices in meat grinding or cutting (FDA, 2009). At the household level, consumer behaviors can enhance risks through lack of information and food safety practices (Fein et al., 2011) as well as cultural traditions of preparation that result in incomplete cooking (Anderson Steeves et al., 2012).

The primary objective of this study was to carry out a pilot study to test the hypothesis that risks of exposure to food borne bacteria and pathogens, and to drug resistant strains, are increased for consumers in neighborhoods with low food access as compared to those with high food access. Because this issue has not been previously studied, a pilot study is an appropriate first step for determining feasibility and likely sample size required for a more rigorous test of this hypothesis. In other studies we have examined household level factors such as food safety knowledge and practices in food selection, handling, preparation and storage (Anderson Steeves et al., 2012).

\section{Methods}

\subsection{Study Site}

The study was carried out in the Baltimore MD (USA) metropolitan area among neighborhoods stratified as high food access (HFA) or low food access (LFA) on the basis of measured characteristics such as SES, housing status, presence or absence of large retail food stores and healthy food availability at these stores. This analysis was separately carried out by Casagrande et al. (2011) prior to our study and the results are mapped in Figure 1a. Standard metrics, including census data on socioeconomic variables as well as assessment of stores in terms of size, numbers of employees, and availability of fresh and healthy foods were utilized in this assessment (Casagrande et al., 2011; O'Connell et al., 2011). From these neighborhoods, we selected those that contained both supermarkets and small grocery stores. Stores classified as "convenience stores" were not included in this study since a preliminary survey by us indicated that none of these outlets carried raw poultry or ground beef products, which were the focus of this study. To reduce other potential sources of variability, all selected neighborhoods were defined by the US Census (2000) as mixed in terms of race, that is, neighborhoods in which no one race or ethnicity accounted for more than $59 \%$ of the population. A map of store locations is shown in Figure 1b. Most stores were located within the city (Figure 1b), and those stores outside the city limits were considered to be within neighborhoods that extended into the city based on resident surveys (Casagrande et al., 2011; O'Connell et al., 2011). 


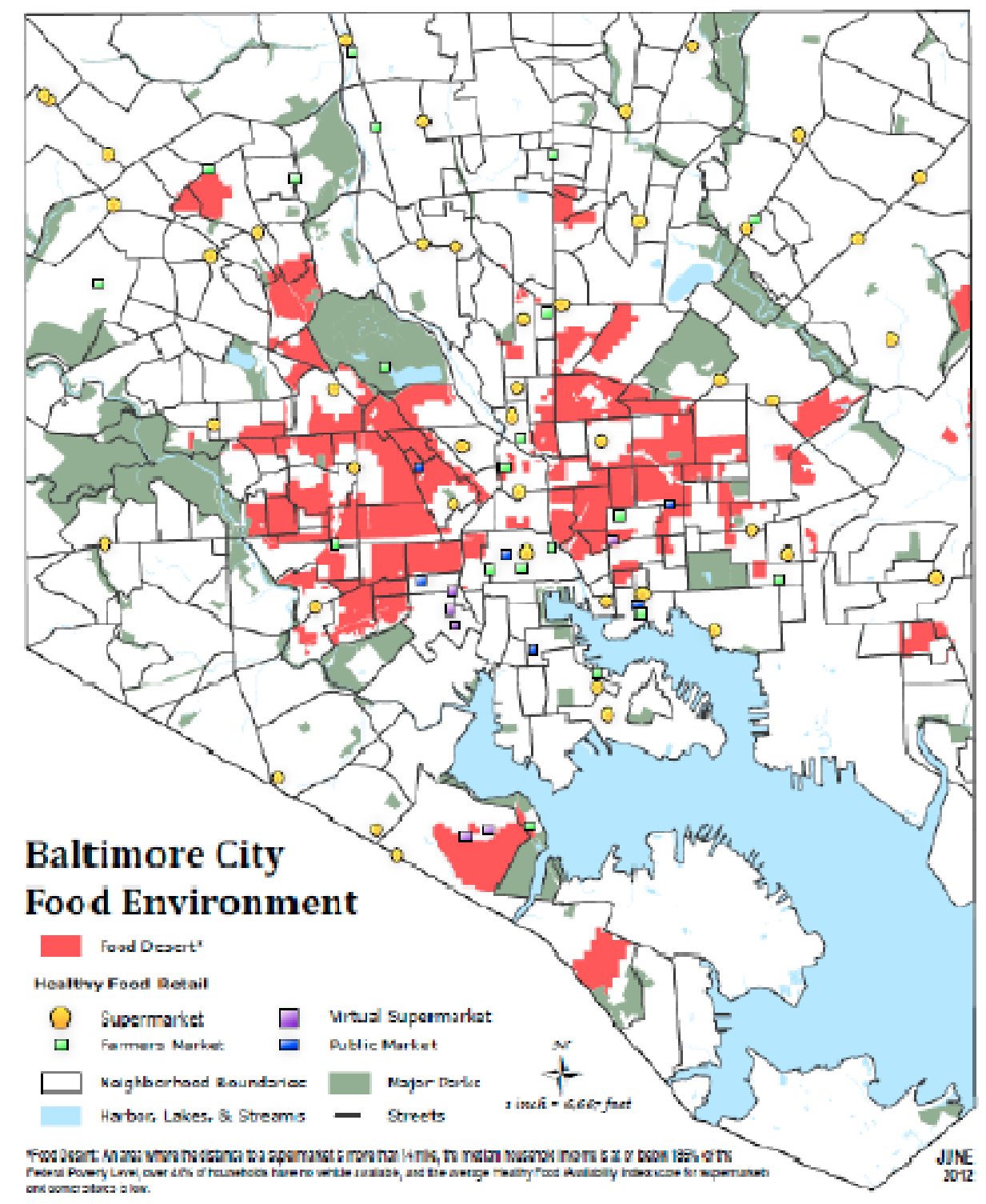

Figure 1a. Food map of Baltimore City (from Johns Hopkins Center for a Livable Future (www.mdfoodsystemmap.org) 


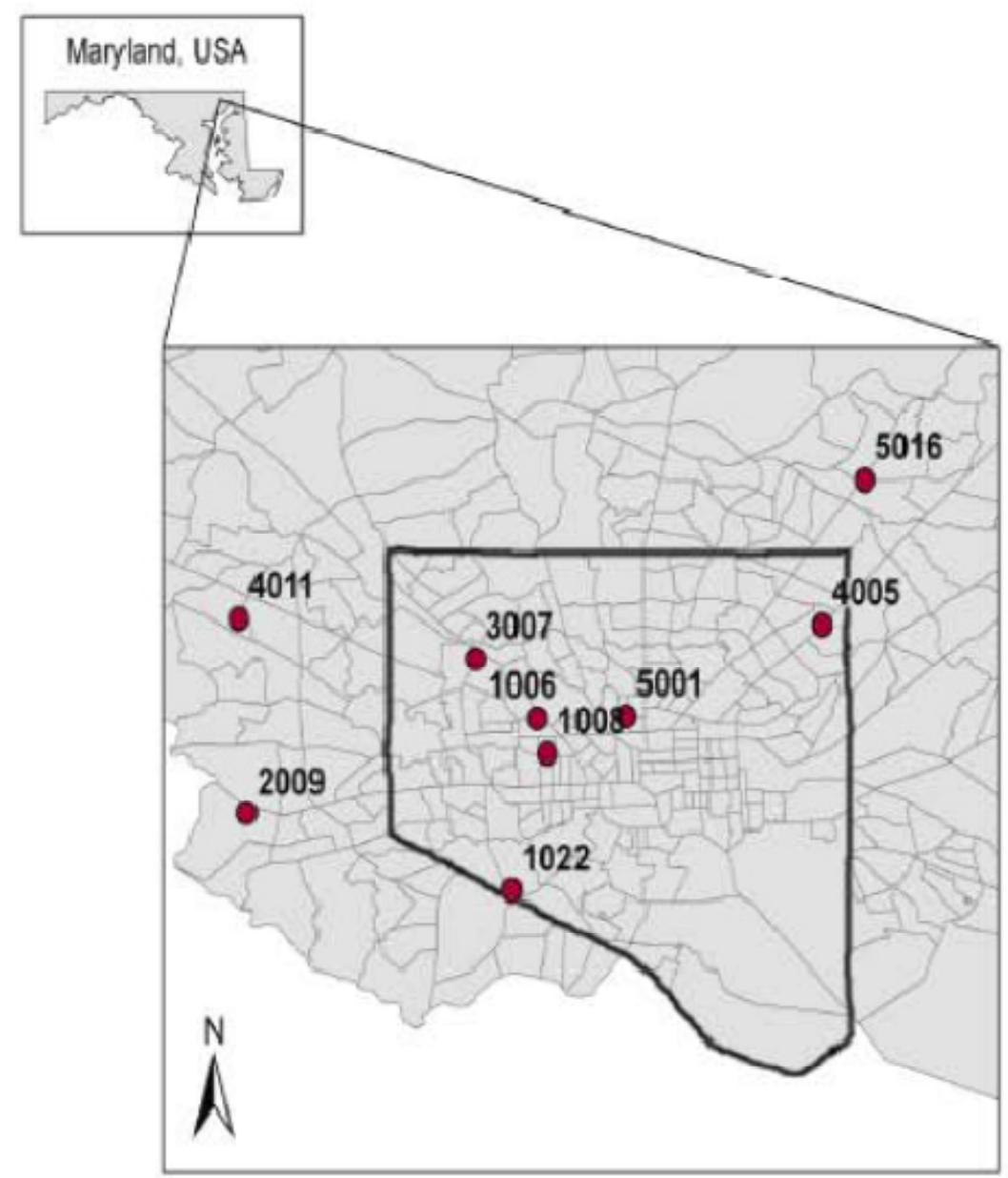

Figure 1b. Map of Baltimore metropolitan area (dark border indicates city boundary). Stores in this study are indicated by red dots and study code numbers

Initially, we randomly selected four stores in each neighborhood, two of which represented smaller stores (selling meat and poultry products) and two of which represented supermarkets (O'Connell et al., 2011). This design was modified by expedience, as many of the LFA areas originally selected did not contain both store types at the time of our survey initiation in 2011. The resulting sample was still drawn from our randomized design. From each outlet, we collected 2 packages each of poultry (thighs) and ground beef over a period of three months, from February to May 2011. For those stores sampled more than once, sampling from the same store was carried out within 7 to 12 weeks of the first visit. We analyzed poultry and ground beef for the following reasons: these are major items in the consumer food basket; they are major components of exposure to food borne pathogens in the US (Zhao et al., 2012); and they represent different producer and retail risk factors relevant to pathogen carriage. That is, in many cases, poultry products are packaged at the processing plant, while ground beef is often prepared at the store or another post-primary processing plant level.

\subsection{Food Sampling}

All food items were unfrozen at the time of purchase. Immediately after purchase the food items were placed in plastic grocery store bags, and transported in coolers without ice to the laboratory within $1 \mathrm{~h}$. Since no quantitation of microbial contamination was planned, changes in bacterial numbers did not affect our study. At the time of purchase, we noted the integrity of packaging, whether the product was wrapped in heavy heat sealed plastic (indicative of packaging at the processing plant) or in thinner material (indicative of post processing rewrap), the presence of information on expiration date, safe food handling and cooking, and the presence of tracer code information. Because no food items labeled as "organic" or "antibiotic free" were available in stores sampled from LFA areas, we only sampled conventionally produced items at all stores. At the lab, each package was labeled with the store of purchase, and then immediately placed in a refrigerator $\left(4^{\circ} \mathrm{C}\right)$ in their original 
packaging until processing. At the time of processing, each package was coded and then photographed to record package information.

\subsection{Microbiological Analyses}

All microbiological analyses were conducted on coded samples to mask identification of source. Analyses were initiated between $10 \mathrm{~min}$ and $3 \mathrm{~h}$ after receipt of samples (time differences related to numbers of samples collected on a given day). We evaluated the presence of two bacterial species, E. coli and Staphylococcus aureus. In other studies, we have examined carriage of Campylobacter jejuni in poultry (Price et al., 2005, 2007). We selected these species since our goal in this study was to utilize the same microbial indicators for both beef and poultry. These two species were selected for different reasons: E. coli are a nearly omnipresent reservoir strain for resistance. We did not define the strain of $E$. coli (with respect to specific pathogenic strains). This method is used by FDA in its surveys of bacterial contamination of retail meats (Zhao et al., 2012). S. aureus (including MRSA) is an increasingly documented food borne disease risk reported to be carried by both beef and poultry products (Hanson et al., 2011; Kelman et al., 2011; Waters et al., 2011).

All packages were opened under sterile conditions and food items were placed in stomacher bags with appropriate broth. Our laboratory methods for E. coli are similar to those of Zhao et al. (2012) and as described in Price (Price et al., 2007); methods for Staphylococcus sp are described in Waters et al. (2011). Briefly, we utilized standard culture methods in which one loop of broth was streaked on appropriate plates and one well-defined colony was selected for further culture, and resistance testing as well as confirmation with PCR ( $S$. aureus) or biochemical testing by indole (E. coli). We tested for antimicrobial resistance using standard disk diffusion assays (CLSI, 2009, M100-S19 http://www.clsi.org), for E. coli isolates: Amikacin (AMK), Ampicillin(AMP), Amoxicilin/Clavulanic acid (AmC), Cefoxitin (CFX) (recommended for methicillin), Ceftriaxone (AXO), Chloramphenicol (CHL), Ciprofloxacin (CIP), Fosfomycin (FOS), Gentamicin (GEN), Imipenem (IMP), Kanamycin (KAN), Nalidixic acid (NAL), Streptomycin (STR), Sulfamethoxazole/Trimethoprim (SXT), and Tetracycline (TET); and for S. aureus isolates: Ampicillin (AMP), Ceftriaxone (AXO), Chloramphenicol (CHL), Ciprofloxacin (CIP), Clindamycin (CLI), Gatifloxacin (GAT), Gentamicin (GEN), Kanamycin (KAN), Levofloxacin (LEVO), Linezolid (LZD), Nitrofurantoin (NIT), Oxacillin (OXA), Penicillin (PEN), Quinupristin/Dalfopristin (SYN), Rifampin (RIF), Sulfamethoxazole/Trimethoprim (SXT), Tetracycline (TET), and Vancomycin (VAN). This list includes antimicrobials from drug classes utilized in poultry and beef production (Zhao et al., 2006; Silbergeld et al., 2008) Reference strains were included at all steps to ensure validity of results: Escherichia coli ATCC 25922; Staphylococcus aureus subsp aureus ATCC 25923; and for MRSA Staphylococcus aureus subsp aureus ATCC 43300 .

\subsection{Definition of Resistance Phenotype}

In reporting the results of resistance testing, we utilized both standard CSLI nomenclature of "susceptible", "intermediate", and "fully resistant", and we also utilized the dichotomous definition of "susceptible" or "nonsusceptible" (to include both intermediate and full resistance phenotypes) as recommended i by Magiorakos et al. (2011) This a consensus report proposes this nomenclature for classifying the results of in vitro testing for purposes of epidemiological and other research, as distinct from testing for clinical purposes, because of different definitions in the literature. This paper also recommends use of the term "MDR" to denote nonsusceptibility to three or more classes of antimicrobial agents.

\section{Results}

\subsection{Summary}

In total, we collected 32 samples of chicken and 32 samples of ground beef from 6 stores in HFA neighborhoods and 3 stores in LFA neighborhoods. In HFA neighborhoods we sampled 2 small stores (both twice) and 4 large stores ( 2 twice, 2 once); in LFA neighborhoods we were able to sample only one large store (twice) and 2 small stores (both twice) due to the lack of retail outlets selling chicken or ground beef in LFA neighborhoods, contrary to the database collected between 1-2 years prior to our study. Repeated sampling was not undertaken to produce replicable results, since shipments of food products occurred throughout the intervening period between sampling; thus each visit was considered as an independent event. In terms of packaging, ground beef samples were more likely to be wrapped loosely (22/32) as compared to chicken (6/32). Most of the heat wrapped ground beef packages came from stores in HFA neighborhoods (one store in a LFA neighborhood from HFA stores sold heat wrapped ground beef) and most of the loosely wrapped chicken packages came from small stores in LFA neighborhoods. All packages contained information on expiration date, safe food handling, preparation, and storage. No package had information relevant to tracking. 


\subsection{Pathogen Prevalence}

The microbiological findings are reported in Table 1.

Table 1. Overall prevalence of bacterial carriage by chicken and ground beef (note that susceptibility testing was only conducted on those items carrying either SA or EC, and multi drug resistance was only tested in those isolates that were nonsusceptible)

\begin{tabular}{lll}
\hline Pathogen & Chicken $(\mathbf{n}=\mathbf{3 2})$ & Ground Beef $(\mathbf{n}=\mathbf{3 2})$ \\
\hline S. aureus & $13 / 32(40 \%)$ & $14 / 32(44 \%)$ \\
Non-susceptible & $9 / 13(69 \%)$ & $11 / 14(79 \%)$ \\
Multi-drug resistant & $2 / 9(22 \%)$ & $4 / 11(36 \%)$ \\
E. coli & $21 / 32(66 \%)$ & $12 / 32(38 \%)$ \\
$\quad$ Non-susceptible & $17 / 21(81 \%)$ & $7 / 12(58 \%)$ \\
Multi-drug resistant & $8 / 17(47 \%)$ & $0 / 7(0 \%)$ \\
\hline \multicolumn{2}{c}{ S. aureus } & \multicolumn{2}{c}{ E. coli } \\
\cline { 2 - 3 } Positive & Positive & Negative \\
Negative & 20 & 7 \\
\hline
\end{tabular}

This table presents data on SA prevalence in all samples, and then on drug resistance in those samples testing positive for SA; thus, the denominators change with the category since not all samples tested positive for SA. In the overall sample set, contamination of both chicken and beef products by $S$. aureus was prevalent $(13 / 32$ or $40 \%$ for chicken and $14 / 32$ or $44 \%$ for beef), while prevalence of $E$. coli was higher in chicken $(21 / 32,66 \%)$ as compared to beef $(12 / 32,38 \%)$. Using the definitions of Magiorakos et al. (2011), there was no difference between chicken and beef in carriage of nonsusceptible or multidrug resistant $S$. aureus (that is, including both intermediate and full resistance in the definition of non-susceptible and for MDRSA) Chicken was more likely to carry nonsusceptible and multidrug resistant strains of $E$. coli as compared to beef. Overall there was a highly significant association between carriage of $S$. aureus and E. coli (both positive and negative) (Pearson chi square 0.004 odds ratio).

Table 2. Prevalence of bacterial carriage by neighborhood and store size. Figures in parentheses are percentages of the preceding row

\begin{tabular}{|c|c|c|c|c|c|c|c|c|}
\hline \multirow{3}{*}{$\begin{array}{l}\text { Neighborhood } \\
\text { Store Size }\end{array}$} & \multicolumn{4}{|c|}{ Chicken } & \multicolumn{4}{|c|}{ Ground beef } \\
\hline & \multicolumn{2}{|c|}{ LFA } & \multicolumn{2}{|c|}{ HFA } & \multicolumn{2}{|c|}{ LFA } & \multicolumn{2}{|c|}{ HFA } \\
\hline & Small & Large & Small & Large & Small & Large & Small & Large \\
\hline S. Aureus & 0 & $2(12.5)$ & $4(25)$ & $7(44)$ & $2(12.5)$ & $5(31)$ & $6(38)$ & $1(6)$ \\
\hline Non-susceptible & & $1(50)$ & $3(75)$ & $5(71)$ & $2(100)$ & $2(40)$ & $6(100)$ & $1(100)$ \\
\hline $\begin{array}{l}\text { Multi Drug } \\
\text { Resistant }\end{array}$ & & $0(0)$ & $1(33)$ & $1(20)$ & $2(100)$ & $0(0)$ & $1(17)$ & $1(100)$ \\
\hline E. Coli & $4(25)$ & $6(38)$ & $6(38)$ & $5(31)$ & $1(6)$ & $3(19)$ & $6(38)$ & $2(12.5)$ \\
\hline Non-susceptible & $3(75)$ & $4(66)$ & $5(83)$ & $5(100)$ & $1(100)$ & $0(0)$ & $4(66)$ & $2(100)$ \\
\hline $\begin{array}{l}\text { Multi Drug } \\
\text { Resistant }\end{array}$ & $2(66)$ & $1(25)$ & $5(100)$ & $0(0)$ & $0(0)$ & $0(0)$ & $0(0)$ & $0(0)$ \\
\hline
\end{tabular}

Table 2 presents data on microbial contamination by neighborhood (HFA or LFA) and by store size (large or small). Given the challenges in locating equal numbers of both tore types in both neighborhood types, we did not attain a sufficient sample size for statistical analysis. The results suggest that store size was more likely to be associated with microbial contamination by nonsusceptible strains of $E$. coli for chicken, with small stores more 
likely to carry MDR strains, while for ground beef, there was a suggestion of more prevalent carriage of nonsusceptible strains of $E$. coliin samples from small stores.

\subsection{Antimicrobial Resistance}

All SA isolates were tested for antimicrobial resistance and, in the case of MRSA, we used PCR to confirm phenotypic results by detection of the $m e c A$ gene. MDR was defined as a phenotype that was nonsusceptible to three or more drugs (Magoriakis et al., 2011). Results are presented in Figure 2 by food product, neighborhood, and store size, for both E. coli and S. aureus in three categories: susceptible, intermediate, and resistant.

\section{E. coli Isolates}

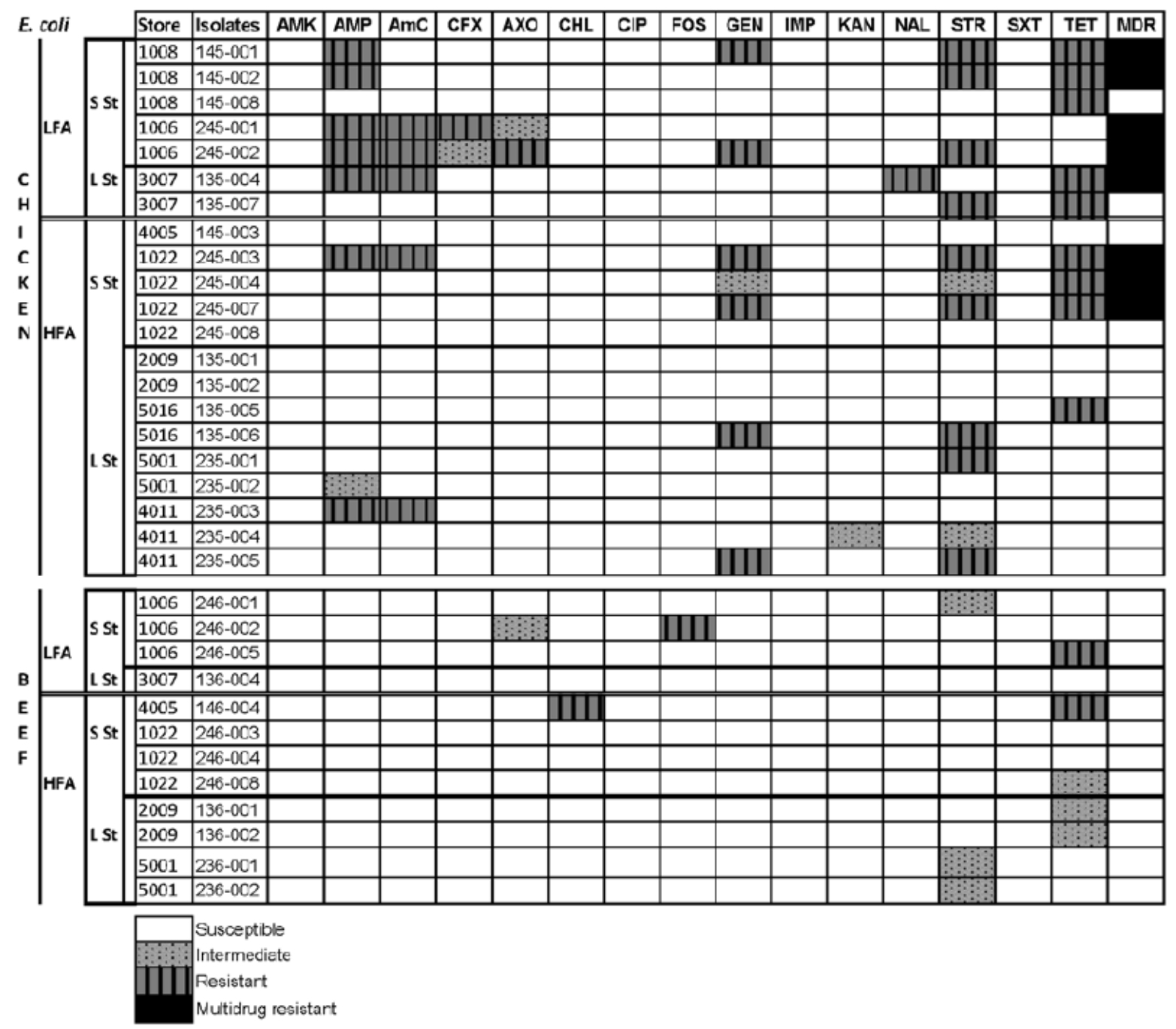




\section{S aureus Isolates}
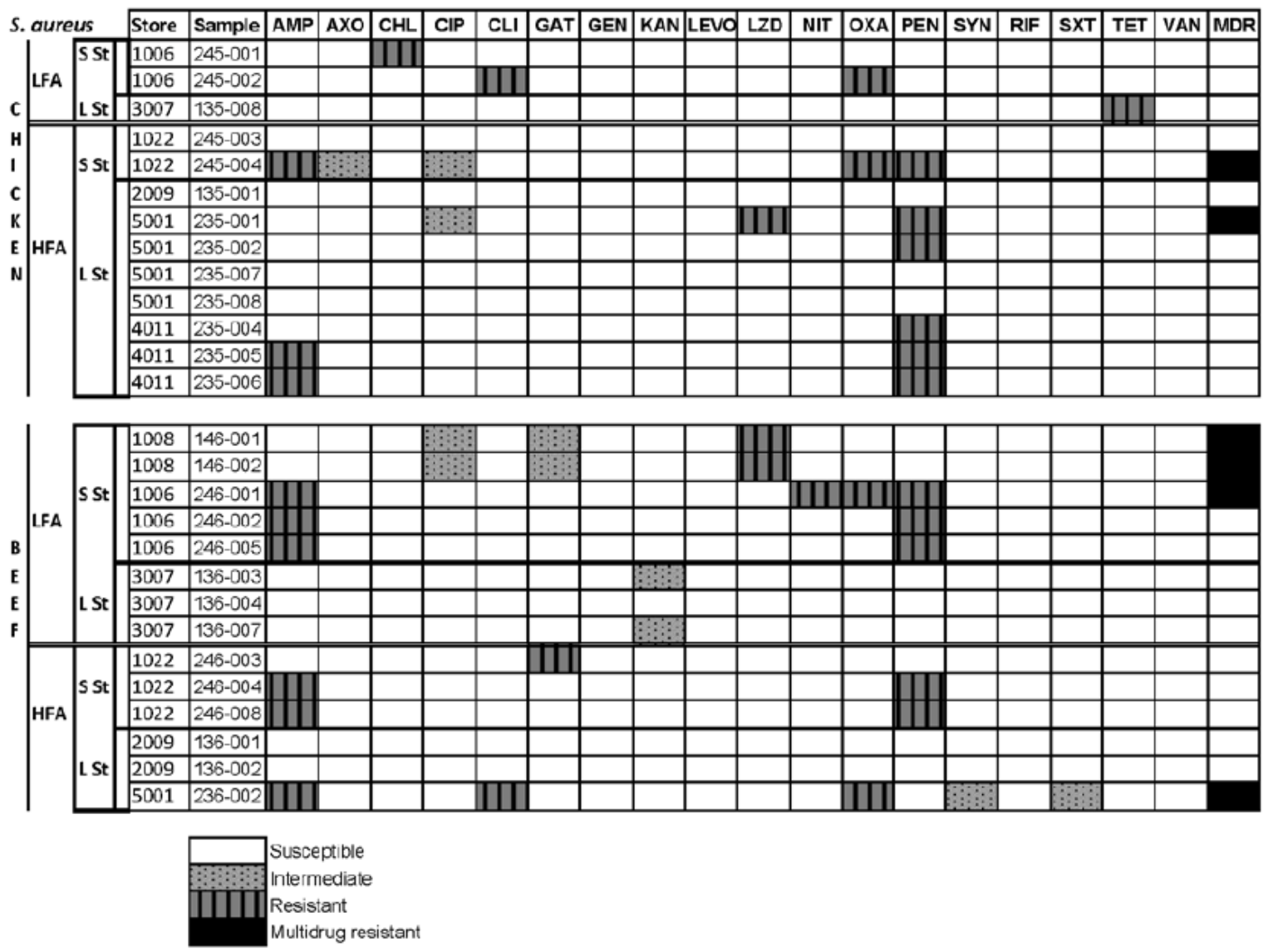

Figure 2. Antibiograms for E. coli and S. aureus isolates from chicken and beef by product, neighborhood, and store size

We analyzed the data in two ways: as two categories of susceptible/nonsusceptible (including intermediate and resistant phenotypes), and as three categories of susceptible/intermediate/fully resistant. As shown in Table 2, there were very few isolates resistant to oxacillin ( $\mathrm{n}=4$ equally distributed by store type and neighborhood) and none of these tested positive for the $m e c A$ gene by PCR. As can be seen from these analyses, chicken and ground beef products from small stores in both HFA and LFA neighborhoods were more likely to carry MDR $S$. aureus. Similarly, small stores in both LFA and HFA neighborhoods were more likely to carry MDR E. coli and small stores in HFA neighborhoods were more likely to carry MDR E. coli as compared to large stores in the same neighborhoods. All isolates were susceptible to vancomycin. Since no isolates were found to be nonsusceptible by disk diffusion assays, we did not carry out further analyses to confirm resistance.

In terms of full resistance, we observed a suggested pattern of greater likelihood of full resistance to the antimicrobials tested for both $S$. aureus and $E$. coli isolates from chicken and ground beef in small as compared to large stores and in small stores in LFA as compared to HFA neighborhoods.

The most commonly observed nonsusceptibility phenotypes (observed in 3 or more isolates) for $S$. aureus in chicken were ampicillin and penicillin, and in beef ampicillin, gatifloxacin and penicillin. For E. coli the most common nonsusceptibility phenotypes were ampicillin and amoxacillin/clavulanic acid, gentamycin, streptomycin and tetracycline in chicken, and streptomycin and tetracycline in beef.

\section{Discussion}

This is the first study on prevalence of microbial contamination of poultry and ground beef products in stores located in neighborhoods differing by food access, including specific pathogen identification and antimicrobial resistance profiles. It complements research by Signs et al. (2011) who assessed nonspecific microbial contamination of ready-to-eat foods as distinct from our study of uncooked consumer meat and poultry products. 
While the sample size was small, some trends are noted. The data from this pilot study suggest that size of store was a factor in the likelihood of microbial contamination and that small stores in LFA neighborhoods appeared to be the most likely to carry fully resistant isolates of both $S$. aureus and E. coli.

The prevalence of microbial contamination in this sample of urban stores from the Baltimore metropolitan region was relatively high although not dissimilar from some recent studies. Our results cannot be compared to these studies since I none of them utilized a sample design intended to compare neighborhood level variables of retail food outlets and their data are not reported with any information on store location or descriptors related to location such as SES. Using data from the National Antibiotic Resistance Monitoring System retail meat program, Zhao et al. (2012) found higher rates of E. coli contamination in a sample of 2988 chicken breasts and 2991 ground beef items. Three recent studies have reported on S. aureus and drug resistant $S$. aureus in the food supply (Hanson et al., 2011; Kelman et al., 2011; Waters et al., 2011). We found similar prevalence of S. aureus as (Kelman et al., 2011; Waters et al., 2011) and higher prevalence than Hanson et al. (2011), a study that did not exclusively focus on ground beef. Similar to Waters et al. (2011) we found no confirmed MRSA. No previous study has reported on correlations between carriage of $S$. aureus and E. coli in either ground beef or chicken; these data are relevant to considerations of food safety. All isolates were susceptible to VAN, which is expected for conventionally produced poultry and meat since vancomycin class drugs were never registered for use as feed additives in North America, in contrast to the EU (Tremblay et al., 2011).

Interestingly, we observed marked decreases in the prevalence of full resistance to ciprofloxacin in isolates from chicken as compared to our studies in 2004 and 2006 conducted before and after the FDA banned the use of ciprofloxacin in poultry feed (Price et al., 2007). In 2006, we found average prevalence of $26 \%$ for full resistance to CIP in Campylobacter jejuni isolates from conventionally raised chicken products in this study, we found no $S$ aureus or E. coli isolates that were fully resistant to CIP and only four S. aureus isolates were intermediate resistant to CIP. This is similar to a recent report on Campylobacter from Canada (Deckert, Valdivieso-Garcia et al., 2010) but lower than that reported in a recent study on S. aureus carriage in the US (Waters et al., 2011). Other observations from this study indicate concerns requiring further investigation. For the first time, we investigated the associations between carriage of $E$. coli and $S$. aureus. There was a highly significant correlation between both positivity and negativity of carriage. This information is relevant to assessing overall health risks as well as designing effective interventions to reduce consumer exposure. The prevalence of loose wrapping of ground beef may be a preventable risk for food contamination. Finally, the absence of label information on producer origin may impede trace backs through the production chain from consumers and retail level to processors and producers.

Overall, this study must be considered as exploratory as it is the first study designed to test associations between food access and food safety. The study is limited by its final sample size and also by lack of information on specific strain level data for E. coli. Our decision not to quantify bacterial presence was related to the lack of information available on factors in the overall food production system, including conditions at the retail outlets from which samples were purchased. Our decision to study E. coli without specification of pathogenic strains was driven by a similar strategy utilized in the most recent large survey of consumer food products reported by the FDA (Zhao et al., 2012). This, along with data on actual food purchases and consumption within these neighborhoods, limit these results in terms of inferences for health risks. We also decided not to quantitfy bacterial contamination in this study since we did not have information on the stages of production from farm through primary and secondary processing owing to lack of label information. Moreover, we were not able to obtain data on store conditions, such as temperature and length of holding, which are key factors in microbial food safety. For these reason, we did not attempt quantitative analyses of microbial contamination, since this would be expected to vary with these conditions.

The study demonstrated challenges to such research as well as the necessity to carry out a a larger project to investigate food safety related to differing conditions of food access. Our decision to design a neighborhood based, rather than city-based, study of this hypothesis resulted in selection of neighborhoods with fewer food stores than had been reported in an earlier survey. Conclusions are also limited because of restriction to one urban area. The results support the need for further systematic investigation of this topic in order to define the risks of food safety related to food access, store size, and other factors. The results suggest that monitoring programs for food borne microbes, conducted by USDA and FDA among others, should include sampling from stores in a range of neighborhoods and that analyses of pathogen prevalence should include information on store type and neighborhood. 


\section{References}

Anderson Steeves, E., Silbergeld, E., Summers, A., Chen, L., \& Gittelsohn. (2012). Risky Food Safety Behaviors Are Associated with Higher Bmi and Lower Healthy Eating Self-Efficacy and Intentions among African American Churchgoers in Baltimore. PLoS One, 7(12), e52122. http://dx.doi.org/10.1371/journal.pone.0052122

Angulo, F. J., Nargund, V. N., \& Chiller, T. C. (2004). Evidence of an association between use of anti-microbial agents in food animals and anti-microbial resistance among bacteria isolated from humans and the human health consequences of such resistance. J Vet Med B Infect Dis Vet Public Health, 51(8-9), 374-379. http://dx.doi.org/10.1111/j.1439-0450.2004.00789.x

Boone-Heinonen, J., Gordon-Larsen, P., Kiefe, C. I. Shikany, J. M., Lewis, C. E., \& Popkin, B. M. (2011). Fast food restaurants and food stores: longitudinal associations with diet in young to middle-aged adults: the CARDIA study. Arch Intern Med., 171(13), 1162-1170. http://dx.doi.org/10.1001/archinternmed.2011.283

Casagrande, S. S., Franco, M., Gittelsohn, J., Zonderman, A. B., Evans, M. K., Fanelli Kuczmarski, M., \& Gary-Webb, T. L. (2011). Healthy food availability and the association with BMI in Baltimore, Maryland. Public Health Nutr, 14(6), 1001-1007. http://dx.doi.org/10.1017/S1368980010003812

Cerin, E., Frank, L. D., Sallis, J. F., Saelens, B. E., Conway, T. L., Chapman, J. E., \& Glanz, K. (2011). From neighborhood design and food options to residents' weight status. Appetite, 56(3), 693-703. http://dx.doi.org/10.1016/j.appet.2011.02.006

Coleman-Jensen, A., Nord, M., Andrews, M., \& Carlson, S. (2011). Household Food Security in the United States in 2010 (p. 37). USDA Economic Research Service (ERR-125).

D'Angelo, H., Suratkar, S., Song, H. J., Stauffer, E., \& Gittelsohn, J. (2011). Access to food source and food source use are associated with healthy and unhealthy food-purchasing behaviours among low-income African-American adults in Baltimore City. Public Health Nutr, 14(9), 1632-1639. http://dx.doi.org/10.1017/S1368980011000498

Darcey, V. L., \& Quinlan, J. J. (2011). Use of geographic information systems technology to track critical health code violations in retail facilities available to populations of different socioeconomic status and demographics. J. Food Prot, 74(9), 1524-1530. http://dx.doi.org/10.4315/0362-028X.JFP-11-101

Deckert, A., Valdivieso-Garcia, A., Reid-Smith, R., Tamblyn, S., Seliske, P., Irwin, R., ... McEwen, S. A. (2010). Prevalence and antimicrobial resistance in Campylobacter spp. isolated from retail chicken in two health units in Ontario. J. Food Prot, 73(7), 1317-1324.

Drewnowski, A. (2004). Obesity and the food environment: dietary energy density and diet costs. Am J. Prev. Med., 27(3 Suppl), 154-162. http://dx.doi.org/10.1016/j.amepre.2004.06.011

Drewnowski, A. (2009). Obesity, diets, and social inequalities. Nutr. Rev., 67(Suppl 1), S36-S9. http://dx.doi.org/10.1111/j.1753-4887.2009.00157.x

FDA. (2009). FDA Report on the Occurrence of Foodborne Illness Risk Factors in Selected Institutional Foodservice, Restaurant, and Retail Food Store Facility Types.

Fein, S. B., Lando, A. M., Levy, A. S., Teisl, M. F., \& Noblet, C. (2011). Trends in U.S. consumers' safe handling and consumption of food and their risk perceptions, 1988 through 2010. J. Food Prot., 74(9), 1513-1523. http://dx.doi.org/10.4315/0362-028X.JFP-11-017

Fuller, D., Cummins, S., \& Matthews, S. A. (2013). Does transportation mode modify associations between distance to food store, fruit and vegetable consumption, and BMI in low-income neighborhoods? Am J. Clin Nutr., 97(1), 167-172. http://dx.doi.org/10.3945/ajen.112.036392

Gillespie, I. A., Mook, P., Little, C. L., Grant, K. A., \& McLauchlin, J. (2010). Human listeriosis in England, 2001-2007: association with neighbourhood deprivation. Euro Surveill, 15(27), 7-16.

Hanson, B. M., Dressler, A. E., Harper, A. L., Scheibel, R. P., Wardyn, S. E., Roberts, L. K., ... Smith, T. (2011). Prevalence of Staphylococcus aureus and methicillin-resistant Staphylococcus aureus (MRSA) on retail meat in Iowa. J. Infect Public Health, 4(4), 169-174. http://dx.doi.org/10.1016/j.jiph.2011.06.001

Hardnett, F. P., Hoekstra, R. M., Kennedy, M., Charles, L., \& Angulo, F. J. (2004). Epidemiologic issues in study design and data analysis related to FoodNet activities. Clin Infect Dis., 38(Suppl 3), S121-S6. http://dx.doi.org/10.1086/381602 
Kelman, A., Soong, Y. A., Dupuy, N., Shafer, D., Richbourg, W., Johnson, K., ... Meng, J. (2011). Antimicrobial susceptibility of Staphylococcus aureus from retail ground meats. J. Food Prot., 74(10), 1625-1629. http://dx.doi.org/10.4315/0362-028X.JFP-10-571

Koro, M. E., Anandan, S., \& Quinlan, J. J. (2010). Microbial quality of food available to populations of differing socioeconomic status. Am J. Prev. Med., 38(5), 478-481. http://dx.doi.org/10.1016/j.amepre.2010.01.017

Larson, N. I., Story, M. T., \& Nelson, M. C. (2009). Neighborhood environments: disparities in access to healthy foods in the U.S. Am J. Prev. Med., 36(1), 74-81. http://dx.doi.org/10.1016/j.amepre.2008.09.025

Lewis, L. B., Sloane, D. C., Nascimento, L. M., Diamant, A. L., Guinyard, J. J., Yancey, A. K., \& Flynn, G. (2005). African Americans' access to healthy food options in South Los Angeles restaurants. Am J. Public Health, 95(4), 668-673. http://dx.doi.org/10.2105/AJPH.2004.050260

Magiorakos, A. P., Srinivasan, A., Carey, R. B., Carmeli, Y., Falagas, M. E., Giske, C. G., ... Monnet, D. L. (2011). Multidrug-resistant, extensively drug-resistant and pandrug-resistant bacteria: an international exper proposal for interim standard definitions for acquired resistance. Clin Microbiol Infect.

NAS. (2011). Hunger and Obesity: Understanding a Food Insecurity Paradigm: Workshop Summary (2011). Washington, DC: National Academies Press.

O'Connell, M., Buchwald, D. S., \& and Duncan, G. E. (2011). Food access and cost in American Indian communities in Washington State. J. Am. Diet. Assoc., 111(9), 1375-9. http://dx.doi.org/10.1016/j.jada.2011.06.002

Oberholser, C. A., \& Tuttle, C. R. (2004). Assessment of household food security among food stamp recipient families in Maryland. Am. J. Public Health, 94(5), 790-5. http://dx.doi.org/10.2105/AJPH.94.5.790

Pires, S. M., Evers, E. G., van Pelt, W., Ayers, T., Scallan, E., Angulo, F. J., ... Hald, T. (2009). Attributing the human disease burden of foodborne infections to specific sources. Foodborne Pathog Dis., 6(4), 417-24. http://dx.doi.org/10.1089/fpd.2008.0208

Powell, L. M., Auld, M. C., Chaloupka, F. J., O'Malley, P. M., \& Johnston, L. D. (2007b). Access to fast food and food prices: relationship with fruit and vegetable consumption and overweight among adolescents. $A d v$ Health Econ Health Serv Res., 17, 23-48. http://dx.doi.org/10.1016/S0731-2199(06)17002-8

Powell, L. M., Slater, S., Mirtcheva, D., Bao, Y., \& Chaloupka, F. J. (2007a). Food store availability and neighborhood characteristics in the United States. Prev Med., 44(3), 189-195. http://dx.doi.org/10.1016/j.ypmed.2006.08.008

Price, L. B., Graham, J. P., Lackey, L. G., Roess, A., Vailes, R., \& Silbergeld, E. K. (2007). Elevated risk of carrying gentamicin-resistant Escherichia coli among U.S. poultry workers. Environ Health Perspect, 115(12), 1738-1742. http://dx.doi.org/10.1289/ehp.10191

Price, L. B., Johnson, E., Vailes, R., \& Silbergeld, E. K. (2005). Fluoroquinolone-resistant Campylobacter isolates from conventional and antibiotic-free chicken products. Environ Health Perspect, 113(5), 557-560. http://dx.doi.org/10.1289/ehp.7647

Price, L. B., Lackey, L. G., Vailes, R., \& Silbergeld, E. K. (2007). The persistence of fluoroquinolone-resistant Campylobacter in poultry production. Environ Health Perspect, 115(7), 1035-1039. http://dx.doi.org/10.1289/ehp.10050

Scallan, E., Hoekstra, R. M., Angulo, F. J., Tauxe, R. V., Widdowson, M. A., Roy, S. L., ... Griffin, P. M. (2011b). Foodborne illness acquired in the United States--major pathogens. Emerg Infect Dis., 17(1), 7-15.

Signs, R. J., Darcey, V. L., Carney, T. A., Evans, A. A., \& Quinlan, J. J. (2011). Retail food safety risks for populations of different races, ethnicities, and income levels. J. Food Prot., 74(10), 1717-1723. http://dx.doi.org/10.4315/0362-028X.JFP-11-059

Silbergeld, E. K., Graham, J., \& Price, L.B. (2008). Industrial food animal production, antimicrobial resistance, and human health. Annu Rev Public Health, 29, 151-169. http://dx.doi.org/10.1146/annurev.publhealth.29.020907.090904

Tremblay, C. L., Letellier, A., Quessy, S., Boulianne, M., Daignault, D., \& Archambault, M. (2011). Multiple-antibiotic resistance of Enterococcus faecalis and Enterococcus faecium from cecal contents in broiler chicken and turkey flocks slaughtered in Canada and plasmid colocalization of tetO and ermB genes. J. Food Prot, 74(10), 1639-1648. http://dx.doi.org/10.4315/0362-028X.JFP-10-451 
Vahabi, M., \& Damba, C. (2013). Perceived barriers in accessing food among recent Latin American immigrants in Toronto. Int J Equity Health, 12(1), 1. http://dx.doi.org/10.1186/1475-9276-12-1

Ver Ploeg, M., \& Breneman, V. (2009). Access to Affordable and Nutritious Food-Measuring and Understanding Food Deserts and Their Consequences: Report to Congress. Washington, DC, U.S. Department of Agriculture Economic Research Service.

Wallace, D. J., Van Gilder, T., Shallow, S., Fiorentino, T., Segler, S. D., Smith, K. E., ... Angulo F. J. (2000). Incidence of foodborne illnesses reported by the foodborne diseases active surveillance network (FoodNet)-1997. FoodNet Working Group. J. Food Prot, 63(6), 807-809.

Waters, A. E., Contente-Cuomo, T., Buchhagen, J., Liu, C. M., Watson, L., Pearce, K., ... Price, L. B. (2011). Multidrug-Resistant Staphylococcus aureus in US Meat and Poultry. Clin Infect Dis., 52(10), 1227-1230. http://dx.doi.org/10.1093/cid/cir181

Zhao, S., Blickenstaff, K., Bodeis-Jones, S., Gaines, S. A., Tong, E., \& McDermott, P. F. (2012). A Comparison of the Prevalence and Antimicrobial Resistance of Escherichia coli from Different Retail Meats in the United States: 2002-2008. Appl Environ Microbiol, 78(6), 1701-1707. http://dx.doi.org/10.1128/AEM.07522-11

Zhao, S., McDermott, P. F., Friedman, S., Abbott, J., Ayers, S., Glenn, A, ... White, D. G. (2006). Antimicrobial resistance and genetic relatedness among Salmonella from retail foods of animal origin: NARMS retail meat surveillance. Foodborne Pathog Dis., 3(1), 106-117. http://dx.doi.org/10.1089/fpd.2006.3.106 